\title{
Yerba mate may prevent diabetes according to a crossover, randomized, controlled study in humans
}

\author{
Beatriz Sarria ${ }^{1}$, Sara Martinez-Lopez ${ }^{2}$, Joaquin García-Cordero ${ }^{3}$, Susana Gonzalez-Ramila ${ }^{1}$, \\ Raquel Mateos ${ }^{1}$ and Laura Bravo \\ ${ }^{1}$ Institute of Food Science, Technology and Nutrition (ICTAN-CSIC), Madrid, Spain, \\ ${ }^{2}$ Universidad Europea, Madrid, Spain and \\ ${ }^{3}$ Institute of Food Science, Technology and Nutrition (ICTAN-CSIC), Madrid, South-Sudan
}

\section{Abstract}

Yerba mate (Ilex paraguariensis) infusions have been shown to reduce plasma glucose in animals and serum lipids in humans. However, the effects of regularly consuming yerba mate on glucose metabolism in humans has been less studied. The objective of the study was to evaluate the effects of regularly consuming yerba mate on diabetes related biomarkers in healthy and moderately hypercholesterolemic people.

A randomized, crossover, controlled study was carried out in normocholesterolemic $(\mathrm{NC}, \mathrm{n}=25)$ and hypercholesterolemic $(\mathrm{HC}, \mathrm{n}$ $=27$ ), non-smoker and non-vegetarian, men and women, with BMI $18-25 \mathrm{~kg} / \mathrm{m}^{2}$. After a run-in stage, the effects of consuming three servings/day of yerba mate in boiled water during 8 weeks (mate stage) were compared with an isotonic drink during the same time (control stage). Along the study, polyphenol rich foods were restricted. At the beginning and the end of each intervention, urine and blood samples were collected. Dietary records and physical activity questionnaires were completed in each stage. Glucose was analyzed using a colorimetric kit (Sprinreact), and insulin, glucagon, C-peptide, glucose-dependent insulinotropic polypeptide (GIP), glucagon-like peptide-1 (GLP-1), plasminogen activator inhibitor-1 (PAI-1), resistin and visfatin were analyzed using Bio-Rad Multiplex Diabetes kits on Bio-Plex MAGPIX system. Results were statistically studied using a mix model with repeated measures and a Bonferroni test within each group (SPSS 23.0).

Nutrient intake and physical activitiy did not show changes along the study. In contrast, fasting levels of glucose, insulin, glucagon, and GLP-1 significantly decreased after the mate stage, showing glucagon a significant yerba mate*group interaction. Attending to these results, it may be concluded that sustained consumption of yerba mate may prevent type 2 diabetes. These outcomes indicate that the effects of yerba mate in pre-diabetes and T2DM subjects are worth further studying.

Funded by the Spanish State Research Agency, projects AGL2010-18269 and AGL2015-69986-R

\section{Conflict of Interest}

There is no conflict of interest 